\title{
PREVALENCE, EPIDEMIOLOGICAL ASPECTS AND CLINICAL IMPORTANCE OF TT VIRUS INFECTION IN SLOVAKIA
}

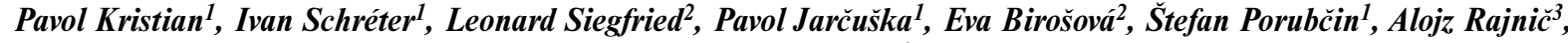 \\ Andrea Gočalová ${ }^{3}$
}

P. J. Safarik University, Faculty of Medicine, Košice, Slovakia: Department of Infectious Diseases ${ }^{1}$, Department of Medical Microbiology ${ }^{2}$, Department of Nephrology ${ }^{3}$

\begin{abstract}
Summary: The aim of the study was to assess the prevalence, clinical impact and importance of different risk factors of transmission of TTV infection in Slovakia using two PCR methods. Sera of 426 adult persons were examined. TTV DNA was identified by PCR using primers from N22 and untranslated region (UTR) respectively. The established prevalence of TTV tested with N22 and UTR primers according to patients groups was: acute hepatitis of unknown etiology 4 resp. 28 of 37, acute hepatitis B 3 resp. 29 of 38, chronic hepatitis B 11 resp. 41 of 44, chronic hepatitis C 10 resp. 93 of 102, hemodialysis patients 13 resp. 72 of 72 , health care workers 0 resp. 27 of 33, control group 8 resp. 83 of 100. Using N22 primers, TTV infection occurred more frequently in chronic hepatitis B group compared with health care workers, if UTR primers were used the group of hemodialysis patients differed significantly from both acute hepatitis groups, health care workers and controls $(\mathrm{p}<0.05)$. From possible risk factors hemodialysis and transfusion count showed notable differences. Bilirubin and aminotransferase levels did not differ between TTV positive and negative groups. No pathogenetic role of TT virus in liver injury was confirmed.
\end{abstract}

Key words: TT virus, Prevalence, PCR, Viral hepatitis, Hemodialysis, Blood transfusions, Pathogenicity

\section{Introduction}

A novel virus, designated TT virus (TTV), was recently reported in Japanese patients with posttransfusion hepatitis of unknown etiology (13). This novel agent is a non-enveloped, circular single-stranded DNA virus, belonging to the family Circoviridae (11). Studies on prevalence of TT virus in general population or in healthy voluntary blood donors in different countries show a high distribution throughout the world (16). Commonly Polymerase Chain Reaction (PCR) based on the N22 region within the open reading frame 1 of viral genome was used for TTV DNA detection. However, another method using primers from untranslated region (UTR) proved a much higher incidence of TTV found in studied population (19). Epidemiological studies have established that the routes of TTV infection might be mostly parenteral (blood transfusions, intravenous drug use, hemodialysis and others), but also fecal-oral route of viral transmission could be possible $(2,14)$. TTV infection is quite frequently observed in HBV and HCV infected patients and also in patients with hepatitis of unknown etiology. Coinfection of $\mathrm{HBV}$ or HCV infected patients with TT virus is reaching up to $40 \%(2,3,6,7)$. No data from Slovakia and only a few from Central and Eastern European countries were published yet.
The principal aims of this study were to assess the prevalence and clinical impact of TTV infection in general population and in patients with different liver diseases in Slovakia and to determine the importance of different risk factors of parenteral virus transmission using PCR methods with two different sets of primers from N22 and untranslated region respectively.

\section{Material and Methods}

\section{Study groups}

We examined sera of total 426 adult persons ( 216 males and 210 females, mean age $41.6 \pm 18.3$ years) taken in years 2001-2004. The patients with diverse risk of parenteral infection and different liver diseases were divided into 7 groups as follows: acute hepatitis of unknown etiology 37 , acute hepatitis B 38, chronic hepatitis B 44, chronic hepatitis C 102, hemodialysis patients 72 , health care workers 33 and control group 100 individuals. The control group consisted of randomly selected patients with acute enteritis but without previously known liver injury and served as a random choice of general population. Anamnestic data were taken and actual bilirubin and aminotranspherase levels were established for examined persons. The viral etiology of cases in four groups with diagnosis of various types 
of hepatitis was proven by examining common viral hepatitis markers, in patients with chronic hepatitis $\mathrm{B}$ and $\mathrm{C}$ the diagnosis was in most cases confirmed also by PCR. The cases with acute hepatitis of unknown etiology had never displayed either any evidence of known hepatotropic infections (i.e., HBV, HCV, HAV, Epstein-Barr virus, Cytomegalovirus) or any other causes of acute liver disorder, such as autoimmune diseases, drugs toxicity and Wilson's disease. Considering the epidemiological situation in Slovak Republic the hepatitis E virus infection was examined only in the cases with recent international travel but without any positive result.

\section{Detection of TTV}

Serum samples obtained from patients were stored frozen at $-80{ }^{\circ} \mathrm{C}$ before testing. DNA extracted from $200 \mu \mathrm{l}$ of serum by QIAamp DNA Blood Mini Kit (QIAGEN) was used as a template for PCR reaction. Each DNA sample was resuspended in $100 \mu \mathrm{l}$ of elution buffer. PCR was performed using two different sets of primers:

1. TTV DNA based on primers from N22 region was identified by semi-nested PCR as described previously by Okamoto (15). A total volume of PCR reaction mixture was $50 \mu \mathrm{l}$. Each tube contained $5 \mu \mathrm{l}$ of template DNA, $1.5 \mathrm{U}$ polymerase (RecTac Taq polymerase, Invitrogen), concentration $0.2 \mathrm{mM}$ of each dNTP (dATP, dTTP, dGTP, dCTP), $1.5 \mathrm{mM} \mathrm{MgCl}_{2}$ and amount 50pM of each of primers. First PCR utilized NG 059 sense primer (5'-ACAGACAGAGGAGAAGGCAACATG-3') and NG 063 antisense primer (5'-CTGGCATTTTACCATTTCCAAAGTT-3'). PCR protocol consisted of initial denaturation $\left(96^{\circ} \mathrm{C} / 6 \mathrm{~min}\right)$ followed by 35 cycles $\left(94{ }^{\circ} \mathrm{C} / 30 \mathrm{~s} ; 60{ }^{\circ} \mathrm{C} / 45 \mathrm{~s}\right.$ and $\left.72{ }^{\circ} \mathrm{C} / 45 \mathrm{~s}\right)$, and final extension $\left(72^{\circ} \mathrm{C} / 2 \mathrm{~min}\right)$. Second PCR was carried out with NG 061 sense primer (5'-GGCAACATGTTGTGGATAGACTGG-3') and the same NG 063 antisense primer for 25 cycles under the same PCR conditions.

2. TTV DNA based on primers from UTR region was identified by PCR protocol as described previously by Takahashi (19). A total volume of PCR reaction mixture was $25 \mu \mathrm{l}$. Each tube contained $5 \mu \mathrm{l}$ of template DNA, $1.5 \mathrm{U}$ polymerase (HotStar Taq polymerase, Quiagen), concen- tration $0.2 \mathrm{mM}$ of each dNTP (dATP, dTTP, dGTP, dCTP), $2.5 \mathrm{mM} \mathrm{MgCl}$, and amount $50 \mathrm{pM}$ of each of primers: T801-sense primer (5'-GCTACGTCACTAACCACGTG-3') and T935-antisense primer (5'-CTBCGGTGTGTAAACTCACC-3', B=G,C alebo T). PCR protocol consisted of initial denaturation $\left(96^{\circ} \mathrm{C} / 15 \mathrm{~min}\right)$ followed by 55 cycles $\left(95^{\circ} \mathrm{C} / 20 \mathrm{~s} ; 65^{\circ} \mathrm{C} / 20 \mathrm{~s}\right.$ and $\left.72{ }^{\circ} \mathrm{C} / 20 \mathrm{~s}\right)$, and final extension $\left(72{ }^{\circ} \mathrm{C} / 2 \mathrm{~min}\right)$.

PCR products ( $271 \mathrm{bp}$ for TTV N22 and $199 \mathrm{bp}$ for TTV UTR region) were detected by agarose gel electrophoresis, with using of $2 \%$ agarose, stained with ethidium bromide, and visualised under UV light. DNA 50-bp ladder (Invitrogen) was used as DNA molecular weight size marker.

\section{Statistical analysis}

The distribution identity of relevant datasets with normal distribution was tested by the Kolomogorov-Smirnov test (K-S-test). In case of negative result the nonparametrical Mann-Whitney U-test was used to test differences in mean values of continuous variables between groups, otherwise the two-tailed Student t-test was performed. Chisquare test according to Bonferroni correction was used to compare the proportions between the groups. Significance was discriminated by a p-value less than 0.05 .

\section{Results}

Overall, TTV DNA based on primers from N22 region was confirmed in 49 patients. Divided into groups: acute hepatitis of unknown etiology 4 out of 37 (10.8\%), acute hepatitis B 3 out of 38 (7.9\%), chronic hepatitis B 11 out of 44 (25.0\%), chronic hepatitis C 10 out of 102 (9.8\%), hemodialysis patients 13 out of $72(18.1 \%)$. There was no case of TTV positivity in the group of 33 health care workers. The occurrence in the control group representing the general population was $8.0 \%$ (Table 1 ). The prevalence of positive patients in groups of chronic hepatitis B and hemodialysis patients was slightly but nonsignificantly higher than in the control group. It was significantly higher only in the group of chronic hepatitis $\mathrm{B}$ in comparison with the group of health care workers $(\mathrm{p}<0.05)$.

Tab. 1: Prevalence of TTV DNA in studied groups using two different sets of primers.

\begin{tabular}{|l|c|c|c|}
\hline Diagnostic group & $\mathrm{n}$ & TTV N22 positive (\%) & TTV UTR positive (\%) \\
\hline Acute hepatitis of unknown etiology & 37 & $4(10.8)$ & $28(75.7)$ \\
\hline Acute hepatitis B & 38 & $3(7.9)$ & $29(76.3)$ \\
\hline Chronic hepatitis B & 44 & $11(25.0)^{*}$ & $41(93.2)$ \\
\hline Chronic hepatitis C & 102 & $10(9.8)$ & $93(91.2)$ \\
\hline Hemodialysis patients & 72 & $13(18.1)$ & $27(81.8)$ \\
\hline Health care workers & 33 & 0 & $83(83.0)$ \\
\hline Control group & 100 & $8(8.0)$ & $373(87.6)$ \\
\hline Overall & 426 & $49(11.5)$ & $\dagger$ \\
\hline
\end{tabular}

*significantly higher compared with the group of health care workers $(\mathrm{p}<0.05)$; ${ }^{\dagger}$ significantly higher compared with the group of acute hepatitis of unknown etiology, acute hepatitis B, health care workers and control group $(p<0.05)$ Chi-square test according to Bonferroni correction was used to compare the proportions between the groups. 
Tab. 2: Comparison of various risk factors of possible parenteral transmission of TTV according to method of detection.

\begin{tabular}{|c|c|c|c|c|c|c|}
\hline \multirow[t]{2}{*}{ Risk factor } & \multicolumn{2}{|c|}{ TTV N22 } & \multirow{2}{*}{$\begin{array}{c}\mathrm{p} \\
\text { value }\end{array}$} & \multicolumn{2}{|c|}{ TTV UTR } & \multirow{2}{*}{$\begin{array}{c}\mathrm{p} \\
\text { value }\end{array}$} \\
\hline & $\begin{array}{c}\text { positive } \\
\mathrm{n}=49\end{array}$ & $\begin{array}{c}\text { negative } \\
\mathrm{n}=377\end{array}$ & & $\begin{array}{l}\text { positive } \\
\mathrm{n}=373\end{array}$ & $\begin{array}{c}\text { negative } \\
\mathrm{n}=53\end{array}$ & \\
\hline Surgeries number ${ }^{*}$ & $1.65 \pm 1.82$ & $1.20 \pm 1.39$ & 0.1342 & $1.30 \pm 1.50$ & $0.87 \pm 1.01$ & 0.0826 \\
\hline Transfusions number ${ }^{*}$ & $1.29 \pm 3.01$ & $1.02 \pm 2.78$ & 0.1818 & $1.17 \pm 2.96$ & $0.23 \pm 0.98$ & 0.0053 \\
\hline Years on hemodialysis ${ }^{*}$ & $0.71 \pm 1.41$ & $0.71 \pm 2.23$ & 0.1678 & $0.80 \pm 2.27$ & $0.02 \pm 0.14$ & 0.0143 \\
\hline Intravenous drug use (years) $^{*}$ & $0.51 \pm 2.41$ & $0.37 \pm 1.42$ & 0.4330 & $0.43 \pm 1.65$ & $0.13 \pm 0.86$ & 0.2444 \\
\hline Professional exposure (years) & $0.49 \pm 3.39$ & $1.88 \pm 6.58$ & 0.1589 & $1.77 \pm 6.44$ & $1.36 \pm 5.34$ & 0.4370 \\
\hline Tattoo $^{\dagger}$ & 4 & 32 & 0.9747 & 32 & 4 & 0.9436 \\
\hline Piercing $^{\dagger}$ & 2 & 12 & 0.8794 & 14 & 0 & 0.3182 \\
\hline
\end{tabular}

* means compared by using Mann-Whitney U-test;

$\dagger$ counts compared by using Chi-square test

Tab. 3: Association between TTV infection and serum bilirubin, AST and ALT levels in different diagnostic groups according to method of virus detection.

\begin{tabular}{|c|c|c|c|c|c|c|}
\hline & \multicolumn{2}{|c|}{ TTV N22 } & \multirow{2}{*}{$\begin{array}{c}\mathrm{p} \\
\text { value }\end{array}$} & \multicolumn{2}{|c|}{ TTV UTR } & \multirow{2}{*}{$\begin{array}{c}\mathrm{p} \\
\text { value }\end{array}$} \\
\hline & positive & negative & & positive & negative & \\
\hline \multicolumn{7}{|c|}{ Acute hepatitis of unknown etiology $(n=37)$} \\
\hline & 4 & 33 & & 28 & 9 & \\
\hline Bilirubin & $100.5 \pm 153.9$ & $87.5 \pm 89.8$ & NA & $98.9 \pm 108.9$ & $57.8 \pm 44.9$ & NS \\
\hline AST & $11.42 \pm 9.79$ & $10.89 \pm 9.24$ & NA & $11.66 \pm 10.03$ & $8.72 \pm 6.02$ & NS \\
\hline ALT & $16.82 \pm 14.83$ & $17.09 \pm 13.51$ & NA & $18.14 \pm 14.56$ & $13.69 \pm 9.66$ & NS \\
\hline \multicolumn{7}{|c|}{ Acute hepatitis B $(\mathrm{n}=38)$} \\
\hline & 3 & 35 & & 29 & 9 & \\
\hline Bilirubin & $309.8 \pm 213.7$ & $146.5 \pm 111.7$ & NA & $158.4 \pm 135.9$ & $162.8 \pm 111,1$ & NS \\
\hline AST & $30.19 \pm 25.10$ & $24.10 \pm 15.60$ & NA & $23.76 \pm 15.25$ & $27.31 \pm 20.09$ & NS \\
\hline ALT & $37.88 \pm 18.91$ & $39.50 \pm 25.50$ & NA & $38.61 \pm 24.15$ & $42.02 \pm 27.70$ & NS \\
\hline \multicolumn{7}{|c|}{ Chronic hepatitis B $(\mathrm{n}=44)$} \\
\hline & 11 & 33 & & 41 & 3 & \\
\hline Bilirubin & $20.3 \pm 10.6$ & $36.6 \pm 91.7$ & NS & $34.0 \pm 82.0$ & $10.5 \pm 3.7$ & NA \\
\hline AST & $3.45 \pm 5.72$ & $2.62 \pm 6.07$ & NS & $2.80 \pm 6.12$ & $3.30 \pm 3.86$ & NA \\
\hline ALT & $7.97 \pm 14.68$ & $2.75 \pm 4.15$ & NS & $4.00 \pm 8.69$ & $5.27 \pm 6.31$ & NA \\
\hline \multicolumn{7}{|c|}{ Chronic hepatitis $\mathrm{C}(\mathrm{n}=102)$} \\
\hline & 10 & 92 & & 93 & 9 & \\
\hline Bilirubin & $15.5 \pm 9.6$ & $14.5 \pm 8.5$ & NS & $14.1 \pm 6.9$ & $19.8 \pm 17.7$ & NS \\
\hline AST & $0.91 \pm 0.40$ & $1.58 \pm 2.42$ & NS & $1.35 \pm 1.71$ & $3.19 \pm 5.22$ & NS \\
\hline ALT & $1.46 \pm 0.74$ & $2.18 \pm 3.40$ & NS & $1.88 \pm 2.51$ & $4.42 \pm 6.93$ & NS \\
\hline \multicolumn{7}{|c|}{ Hemodialysis patients $(\mathrm{n}=72)$} \\
\hline & 13 & 59 & & 72 & 0 & \\
\hline Bilirubin & $6.9 \pm 2.2$ & $6.8 \pm 2.5$ & NS & $6.8 \pm 2.4$ & - & NA \\
\hline AST & $0.30 \pm 0.08$ & $0.30 \pm 0.21$ & NS & $0.30 \pm 0.19$ & - & NA \\
\hline ALT & $0.32 \pm 0.22$ & $0.30 \pm 0.21$ & NS & $0.30 \pm 0.21$ & - & NA \\
\hline \multicolumn{7}{|c|}{ Control group $(\mathrm{n}=100)$} \\
\hline & 8 & 92 & & 83 & 17 & \\
\hline Bilirubin & $15.8 \pm 10.8$ & $12.9 \pm 7.4$ & NS & $12.8 \pm 7.6$ & $14.8 \pm 8.3$ & NS \\
\hline AST & $0.43 \pm 0.11$ & $0.47 \pm 0.36$ & NS & $0.48 \pm 0.37$ & $0.38 \pm 0.13$ & NS \\
\hline ALT & $0.26 \pm 0.15$ & $0.42 \pm 0.46$ & NS & $0.44 \pm 0.48$ & $0.28 \pm 0.13$ & NS \\
\hline
\end{tabular}

Biochemical values represent the mean values \pm standard deviation. Normal ranges and units: bilirubin $\leq 21,0 \mu \mathrm{mol} / 1$, AST $\leq 0.66 \mu \mathrm{kat} / 1, \mathrm{ALT} \leq 0.66 \mu \mathrm{kat} / 1$. Mean values were compared by using the two-tailed Student t-test. NS $=$ non-significant. $\mathrm{NA}=$ not applicable. 
If the primers from UTR region were used TTV DNA was confirmed overall in 373 patients. Divided into groups: acute hepatitis of unknown etiology $28(75.7 \%)$, acute hepatitis B 29 (76.3\%), chronic hepatitis B 41 (93.2\%), chronic hepatitis C 93 (91.2\%), hemodialysis patients 72 (100.0\%), health care workers 27 (81.8\%) and control group $83(83.0 \%)$ (Table 1). The prevalence of TTV positive patients was significantly higher in the group of hemodialysis patients compared with the group of acute hepatitis of unknown etiology, acute hepatitis $\mathrm{B}$, health care workers and control group $(\mathrm{p}<0.05)$. Occurence in the chronic hepatitis B and C groups also exceeded $90 \%$ but did not significantly differ from other groups. Primers designed in a untranslated region provided generally much higher prevalences. All of 49 patients previously tested TTV positive by the N22 method were TTV positive by UTR method as well.

The mean age of TTV N22 positive patients was higher than that of the negatives $(45.9 \pm 20.2$ vs $41.0 \pm 18.0$ years $)$ however without statisticaly notable difference. It was significantly higher only in the control group $(59.0 \pm 23.1$ vs $43.6 \pm 19.1$ years, $p<0.05)$. Using the UTR primers there was a notable age difference between positive and negative subgroups $(42.4 \pm 18.8$ vs $35.4 \pm 13.4$ years, $p<0.05)$. No significant differences in gender ratio according to presence of TTV infection proved by both methods of virus detection were observed.

Next we evaluated the possible importance of various risk factors of parenteral transmission of TTV comparing TTV positive and negative patients subgroups. The results differed depending on the method of TTV DNA detection. If N22 primers were used, we found only the average count of surgeries in anamnesis per patient and the number of transfusions in positive patients slightly but nonsignificantly higher than in the negative subgroup (Table 2). By contrast, using UTR primers the number of transfusions and the time on hemodialysis represented a significant risk of TTV infection. The mean number of transfusions was $1.17 \pm 2.96$ vs $0.23 \pm$ $0.98(\mathrm{p}<0.01)$ and the time on hemodialysis was $0.80 \pm 2.27$ vs $0.02 \pm 0.14$ years $(p<0.05)$ in TTV UTR positive and negative patients respectively. Other risk factors as intravenous drug use, tattoo, piercing or professional exposure showed independently on method of virus detection no significant differences for TTV infection in our study (Table 2). The prevalence of TTV infection in 30 persons with history of intravenous drug use from the entire studied cohort (27 with chronic hepatitis $\mathrm{C}$ and 3 hemodialysis patients) was $10.0 \%$ and $96.7 \%$ using the N22 and UTR primers respectively. We found $18(36.7 \%)$ of 49 TTV positive patients without any risk of parenteral transmission of infection.

To elucidate a possible role of TT virus in hepatic pathogenicity we evaluated the association between TTV infection and serum bilirubin, AST and ALT levels in each diagnostic group separately. Using both methods of virus detection the followed biochemical parameters did not significantly differ between TTV positive and negative patients in any diagnostic group (Table 3 ).

\section{Discussion}

The prevalence of TTV infection based on N22 primers in control group of $8.0 \%$ observed in our study corresponds with literature data ranging in developed countries between $1.9 \%$ and $37 \%$ among blood donors or healthy controls $(2,3,6,10,16)$. In comparison with some neighbouring countries as Czech republic (13.5\%) or Hungary (18.5\%) we noticed a slightly lower occurrence $(8,18)$.

If using the primers from UTR region our prevalence in control group $(83 \%)$ was similar to those found in other prevalence studies. The reported numbers of TTV positive subjects are between $78 \%$ and $92 \%(1,12,19)$, although TTV viremia detected in US blood donors was only $41.6 \%$ (4).

We confirmed the highest number of TTV positive patients in chronic hepatitis B and hemodialysis patients groups. The prevalence of TTV infection among hemodialysis patients reported by other authors is similar to our $(5,9)$ or even higher $(21)$. The prevalence in chronic hepatitis B group matches that of observations in other countries ranging between $17.9 \%$ to $35 \%(2,7,10)$. On the other hand the rate of TTV positives among the acute hepatitis B patients was lower than $13.2 \%$ to $24 \%$ reported by other authors $(3,6)$. Surprisingly we noticed also a relatively low TTV incidence in the chronic hepatitis $\mathrm{C}$ group similar to $8.1 \%$ observed by French authors (20), but much lower than over $30 \%$ refered by others $(2,7)$. However if primers from UTR region were used the incidence exceeded $90 \%$ similar to chronic hepatitis B group. The prevalence in patients with acute hepatitis of unknown etiology reached only $10.8 \%$ and appeared to be comparable with the control group, what was in accordance with other authors $(3,10)$.

Concluding from the results obtained with UTR primers a possible association between age and TTV prevalence could be considered. A slight age difference between TTV positive and negative patients tested with N22 primers was observed as well, especially in the control group. An increase in the TTV prevalence with age in adults was noticed similarly by other authors (17). No association between gender and rate of TTV infection was found in our study.

The parenteral route of TT virus transmission mainly by blood exposure or intravenous drug use is an important consideration $(2,13,17)$, therefore we tried to determine its importance in our cohort of patients. In connection with different risk factors of parenteral transmission of TTV tested with N22 primers only the number of surgeries and transfusions came to the fore, but in both cases without statistical significance. However if UTR primers were used hemodialysis and transfusions seemed to be notable risk factors of TTV transmission. Other followed factors as intravenous drug use, tattoo or piercing showed independently on method of virus detection no importance for TTV infection in our study. We noticed also a remarkable number of TTV positive patients without any risk factor of parenteral transmission what suggests another, non-parenteral route of transmission. Observations of other authors support this 
possibility as well $(2,14)$. According to our results the professional exposure of health care workers doesn't belong to risk factors of TT virus infection.

Comparing the laboratory parameters of liver injury in TTV positive and negative patients we did not observed any differences in bilirubin, AST and ALT levels. In accord with other studies we did not observe any influence of TTV infection on the course of illnesses in our patients or worsening of the laboratory findings in the control group $(3,6,7,9,17)$.

\section{Conclusion}

The prevalence of TTV infection in Slovakia matches that of observations in other countries. We found a higher number of TTV positive patients in the group of chronic hepatitis $\mathrm{B}$ and hemodialysis patients. Most important risk factors in connection with parenteral transmission of TTV were hemodialysis and number of transfusions. According to our findings we did not confirmed a pathogenetic role of TT virus in liver injury. These results are the first information about prevalence of TTV infection in Slovakia.

\section{Acknowledgements}

We are grateful to Dr. Benadik Smajda and Prof. Dr. Miroslav Mikulecky for the statistics analysis.

This work was supported by the grant No.1/9330/02 of the Scientific Grant Agency of the Ministry of Education of Slovak Republic and the Slovak Academy of Sciences.

\section{References}

1. Bassit L, Takei K, Hoshino-Shimizu S et al. New prevalence estimate of TT virus (TTV) infection in low- and high-risk population from Sao Paulo, Brazil. Rev Inst Med trop S. Paulo 2002:44:233-4.

2. Colombatto P, Brunetto MR, Kansopon J et al. High prevalence of G1 and G2 TT virus infection in subjects with high and low blood exposure risk: identification of G4 isolates in Italy. J Hepatol 1999;31:990-6.

3. Fabris P, Biasin MR, Infantolino D et al. TTV infection in patients with acute hepatitis of defined aetiology and in acute non-A-E hepatitis. J Hepatol 2000; 32:661-5.

4. Handa A, Dickstein B, Young NS, Brown KE. Prevalence of the newly described human circovirus, TTV, in United States blood donors. Transfusion 2000; 40:245-51.

5. Kanamoto-Tanaka Y, Furusyo N, Nakashima H, Etoh Y, Kashiwagi S, Hayashi J. TT-virus infection in Japanese general population and in hemodialysis patients. Dig Dis Sci 2002;47:1915-20.

6. Kanda T, Yokosuka O, Ikeuchi T et al. The role of TT virus infection in acute viral hepatitis. Hepatology 1999;29:1905-8.
7. Kao JH, Chen W, Chen PJ, Lai MY, Chen DS. TT virus infection in patients with chronic hepatitis B or C: influence on clinical, histological and virological features. J Med Virol 2000;60:387-92.

8. Krekulova L, Rehak V, Killoran P, Madrigal N, Riley LW. Genotypic distribution of TT virus (TTV) in a Czech population: evidence for sexual transmission of the virus. J Clin Virol 2001;23:31-41.

9. Martinez NM, Garcia F, Garcia-Valdecasas J et al. Prevalence and viral persistence of TT virus in patients on hemodialysis. Eur J Clin Microbiol Infect Dis 2000;19:878-80

10. Masia G, Ingianni A, Demelia L et al. TT virus infection in Italy: prevalence and genotypes in healthy subjects, viral liver disease and asymptomatic infections by parenterally transmitted viruses. J Viral Hepat 2001;8:384-90.

11. Miyata $\mathrm{H}$, Tsunoda $\mathrm{H}$, Kazi $\mathrm{A}$ et al. Identification of a novel GC-rich 113-nucleotide region to complete the circular, single-stranded DNA genome of TT virus, the first human circovirus. J Virol 1999;73:3582-6.

12. Nishiguchi S, Enomoto M, Shiomi S et al. TT virus infection in patients with chronic liver disease of unknown etiology. J Med Virol 2000;62:392-8.

13. Nishizawa T, Okamoto H, Konishi K, Yoshizawa H, Miyakawa Y, Mayumi M. A novel DNA virus (TTV) associated with elevated transaminase levels in posttransfusion hepatitis of unknown etiology. Biochem Biophys Res Commun 1997;241:92-7.

14. Okamoto H, Akahane Y, Ukita M et al. Fecal excretion of a nonenveloped DNA virus (TTV) associated with posttransfusion non-A-G hepatitis. J Med Virol 1998;56:128-32.

15. Okamoto $\mathrm{H}$, Nishizawa $\mathrm{T}$, Kato $\mathrm{N}$ et al. Molecular cloning and characterization of a novel DNA virus (TTV) associated with posttransfusion hepatitis of unknown etiology. Hepatol Res 1998;10:1-16.

16. Prescott LE, Simmonds P. Global distribution of transfusion-transmitted virus. N Engl J Med 1998;339:776-7.

17. Salakova M, Nemecek V, Konig J, Tachezy R. Age-specific prevalence, transmission and phylogeny of TT virus in the Czech Republic. BMC Infect Dis 2004 Dec 3;4(1):56. [Epub ahead of print]. Available from URL: http://www.biomedcentral.com/ bmcinfectdis/

18. Takacs M, Balog K, Toth G et al. TT virus in Hungary: sequence heterogenity and mixed infections. FEMS Immunol Med Microbiol 2003;35:153-7.

19. Takahashi K, Hoshino H, Ohta Y, Yoshida N, Mishiro S. Very high prevalence of TT virus (TTV) infection in general population of Japan revealed by a new set of PCR primers. Hepatol Res 1998;12:233-9.

20. Trimoulet $\mathrm{P}$, de Ledinghen V, Ekouevi $\mathrm{D}$ et al. TT virus infection during chronic hepatitis C. Am J Gastroenterol 2000;95:1765-9.

21. Valtuille R, Frankel F, Gomez F et al. The role of transfusion-transmitted virus in patients undergoing hemodialysis. J Clin Gastroenterol 2002;34:86-8.

Submitted October 2005.

Accepted March 2006.

MUDr. Pavol Kristian, Ph. D.,

P. J. Safarik University,

Faculty of Medicine,

Department of Infectious Diseases,

Rastislavova 43,

04190 Košice,

Slovakia.

e-mail: kristian@fnlp.sk 